\title{
Fluid-Dynamic Study of the Avilés Port. Remedial Measures on the Environmental Impact of the Exterior Storage of Powdery Products ${ }^{+}$
}

\author{
Manuel Armindo Guerrero *, Rubén Cordero, Julio Jorge and Francisco J. Vigil \\ ITMA Materials Technology, Engineering Area, Calafates 11, 33417 Avilés, Asturias, Spain; \\ r.cordero@itma.es (R.C.); j.jorge@itma.es (J.J.); f.vigil@itma.es (F.J.V.) \\ * Correspondence: m.armindo@itma.es; Tel.: +34-985-129-120 \\ + Presented at the 2nd International Research Conference on Sustainable Energy, Engineering, Materials and \\ Environment (IRCSEEME), Mieres, Spain, 25-27 July 2018.
}

Published: 8 November 2018

\begin{abstract}
Ports are one of the most commonly used places to perform the exterior storage of powdery products and as a consequence their surrounding areas usually face important problems of pollution. The Avilés Port, located in Asturias at the centre of the northern coast of Spain, asked for a fluid-dynamic study of their docks under the hypothesis of maximum capacity of powdery products, considering different piles of carbon, clinker, zinc concentrate and phosphates, in order to analyse: (a) the environmental impact under the two predominant winds in the port, east and north-east at the maximum wind speed, (b) different options of wind fences (location, gap to the piles, height and porosity) as a remedial measure, (c) the environmental impact of placing the proper wind fences along all the docks. The analyses were carried out by means of numerical simulation using the software ANSYS-CFX ${ }^{\circledR}$ and according to EPA "AP-42. Compilation of Air Pollutant Emission Factors" showed a pollutant emission reduction of 50\% using the final strategy of wind fences decided by the Avilés Port Authority.
\end{abstract}

Keywords: port pollution; fluid-dynamic; simulation

\section{Introduction}

The Avilés Port has more than $37,000 \mathrm{~m}^{2}$ available for the storage of goods and it has more than $2.5 \mathrm{~km}$ of loading quay, with a range of depths from 8 to $14 \mathrm{~m}$. This port manages annually six million tonnes with different goods, which can be classified as follows: solid bulk $(62 \%)$, liquid bulk $(11 \%)$ and general goods $(27 \%)$, so that, more than 3.5 million tonnes of solid bulks are handled annually, with different powdery products: carbon, clinker, zinc concentrate and phosphates.

The accumulation without exhaustive control of these powdery materials can cause high concentration of suspension particles decreasing the air quality not only in the port but also in the surrounding areas. According to Barbara J. B. et al. [1], wind erosion causes an estimated $30 \%$ of storage pile fugitive dust emission, load-in and load-out processes $30 \%$ and vehicular traffic cause the remainder $40 \%$. That is why, in order to reduce the suspension particles generated by the port, the Avilés Port Authority implemented a continuous improvement process in its environmental management.

Thus, a fluid-dynamic study of the docks port was performed to obtain the needed information to take decisions with the final aim of having under control the emissions due to erosion wind on the piles storage in the Avilés Port. Only the results belonging to the left bank of the Avilés Port, which consists of the following loading docks: west, south, Raíces and Raíces enlargement, are included in this proceeding. 


\section{Materials and Methods}

Using ANSYS-CFX software [2], a fluid-dynamic study of the Avilés Port docks was performed in order to obtain the suspension particles generated under different hypothesis agreed with the Port Authority:

- Maximum stored capacity of powdery products, considering different piles of carbon, clinker, zinc concentrate and phosphates. The location, size, height and material of piles vary from time to time so that the situation considered in the analyses was agreed with the Port Authority.

- Two predominant winds, east and north-east at the maximum wind speed.

- Period of study, one year.

- Different options of wind fences (location, gap to the piles, height and porosity) as a remedial measure.

Later on, by using the EPA formulation [3], the emissions generated by each pile, and so the whole port, due to wind erosion (PM10 particles size) was obtained under two situations: (a) initial, docks as it stood, without remedial measures, and (b) after placing different solutions of wind fences along the docks (agreed with Port Authority, avoiding inconveniences during the daily port operation). Finally, the comparison of the results under both situations allows to know the efficiency of the of wind fences and so the environmental impact of placing the proper wind fences along the docks.

\subsection{Methology}

EPA [3] presents the results derived from wind tunnel studies for two representative pile shapes (conical and oval with flattop, $37^{\circ}$ side slope), showing the ratios of surface wind speed to approach wind speed $\left(\mathrm{u}_{\mathrm{s}} / \mathrm{ur}_{\mathrm{r}}\right)$. Figure 1 depicts the results corresponding to a $11 \mathrm{~m}$ height actual pile, a $10 \mathrm{~m}$ height reference (upwind) anemometer, and $0.5 \mathrm{~cm}$ height pile surface roughness. The measured surface winds correspond to $25 \mathrm{~cm}$ height above the surface.
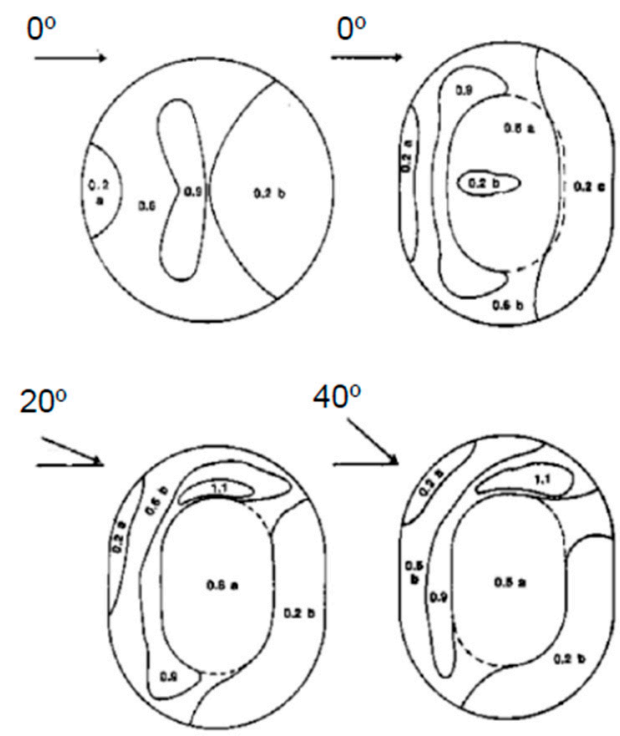

Figure 1. EPA Contours of normalized surface wind speeds [3].

A fluid-dynamic model was developed in order to obtain these contours of normalized surface wind speeds over all the piles located along the Avilés Port docs, where different shapes of piles can be found: lengthwise, conical, conical with flattop, oval, oval with flattop, etc. 


\subsection{Gometrical and Finite Volume Models of the Avilés Port}

The general geometrical model of the Avilés Port was generated from the topographic drawings provided by the Port Authority and measurements on site. Later on, two different geometrical models were used, as it was mentioned: firstly the initial situation, as it stood, without remedial measures, and second after placing the wind fences.

Figure $2 \mathrm{a}$ depicts the main characteristics of the geometrical model -control volume- aim of study. Figure $2 b, c$ show respectively some details of the same area of the port before and after the wind fences were placed. In these pictures can also be distinguished piles, buildings, initial and final wind fences, etc.

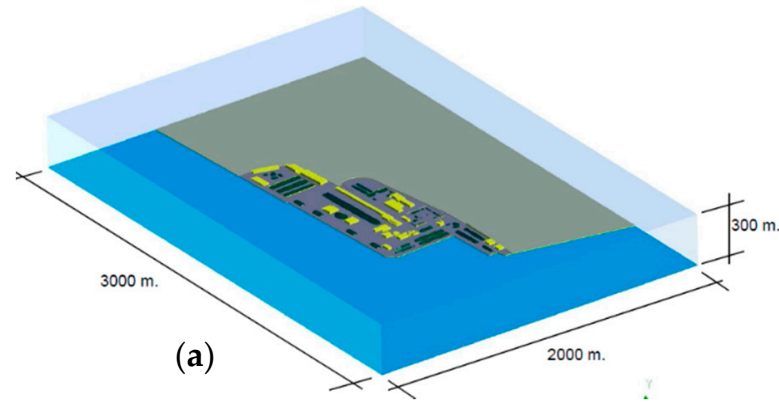

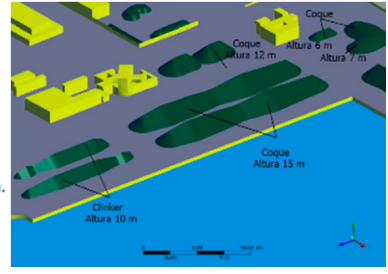

(b)

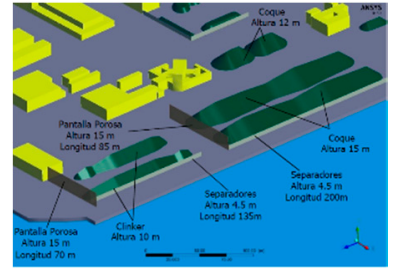

(c)

Figure 2. (a) Characteristics of the control volume aim of study; (b) Initial situation; (c) Finally, with wind fences.

The finite volume models were generated from the above geometrical models. A $50 \mathrm{~m}$ element size was used as general size, refining it close to the piles, to $5 \mathrm{~m}$, and more, $0.9 \mathrm{~m}$, just in the critical areas aim of analysis. Figure $3 a, b$ show two examples of the generated finite volume models. Besides, an inflate layer with eight layers was used just in the boundary of the model where a more accurate resolution of the problem equations were needed.
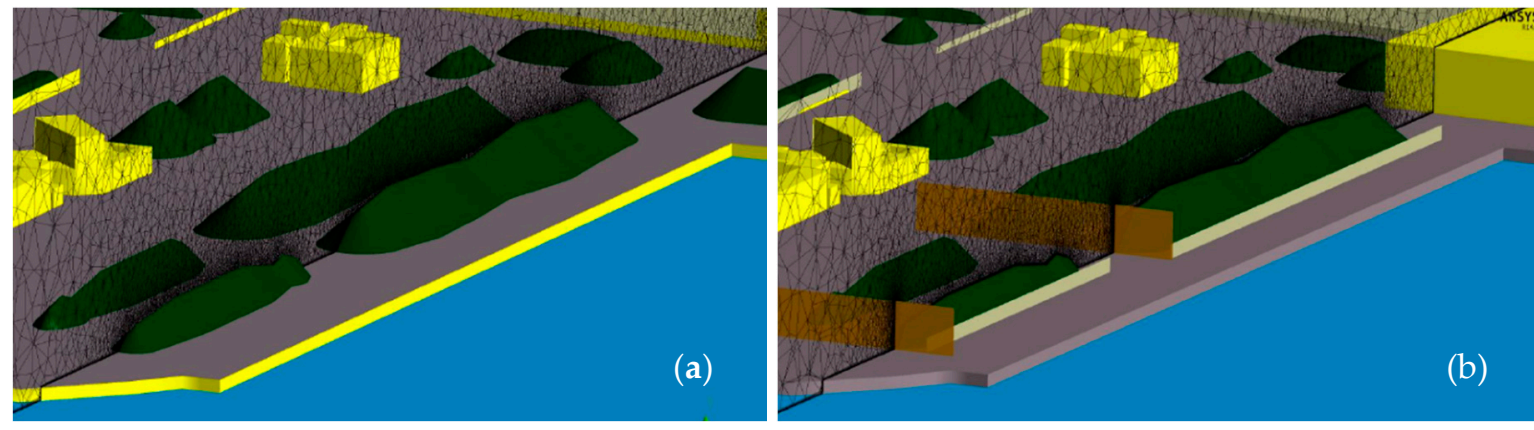

Figure 3. Finite volume model details; (a) Initial situation; (b) Finally, with wind fences.

\subsection{Wind Velocity}

From the analysis of the historical data of the wind speed in the Avilés Port there were identified two directions as the most interesting for the study, east and north-east. Thus, the fastest mile of wind for the periods between disturbances $8.65 \mathrm{~m} / \mathrm{s}$ and $8.57 \mathrm{~m} / \mathrm{s}$ as well as logarithmic wind speed profile were used respectively.

Besides, a typical roughness height of $0.03 \mathrm{~m}$ for open terrain with isolated obstacles and 0.0002 $\mathrm{m}$ as roughness height for the sea were used.

\subsection{Fluid Dynamic Analyses}

Two steady state and isothermal $\left(20^{\circ} \mathrm{C}\right)$ fluid dynamic analyses were performed, one for each situation. The physical properties of air from ANSYS-CFX library were used as material properties [2]. 
The equations solved in the analysis were: continuity and momentum, on the other hand the K$\varepsilon$ turbulence model was employed as the results obtained fit better the contours of normalized surface wind speeds presented in the EPA [3].

\section{Results}

The ratios of surface wind speed to approach wind speed $\left(\mathrm{u}_{\mathrm{s}} / \mathrm{ur}_{\mathrm{r}}\right)$ were obtained at $25 \mathrm{~cm}$ height above the surface of each pile. As an example, Figure 4 depicts the velocity distribution due to east wind in the initial situation and Table 1 summarises the particles emission reduction in some piles.

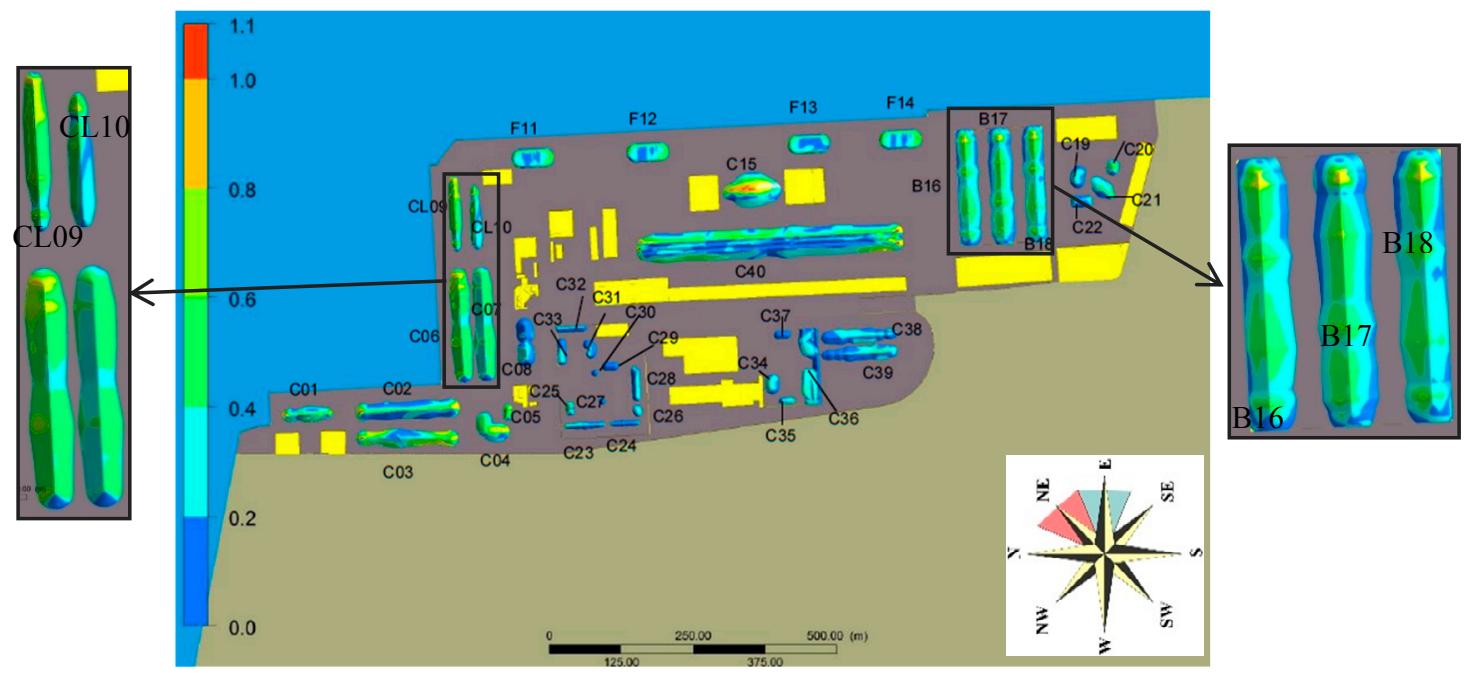

Figure 4. Ratios of surface wind speed to approach wind speed. Initial situation.

Table 1. Particles emission reduction.

\begin{tabular}{cccccccccc}
\hline Pile \# & C15 & C40 & B16 & B17 & B18 & CL09 & C10 & F11 & F12 \\
\hline Reduction (E wind) & $24 \%$ & $6 \%$ & $57 \%$ & $54 \%$ & $82 \%$ & $92 \%$ & $96 \%$ & $48 \%$ & $78 \%$ \\
Reduction (NE wind) & $47 \%$ & $10 \%$ & $21 \%$ & $49 \%$ & $58 \%$ & $42 \%$ & $53 \%$ & $26 \%$ & $48 \%$ \\
\hline
\end{tabular}

\section{Discussion}

The comparative analysis of emissions obtained in both situations show a reduction of $60 \%$ and $43 \%$ under east and north-east winds respectively after placing the wind fences.

Acknowledgement: ITMA thanks Avilés Port Authority the economic support as well as the data provided and the measurement performed in its facilities.

\section{References}

1. Billman Stunder, B.J.; Arya, S.P.S. Windbreak Effectiveness for Storage Pile Fugitive Dust Control: A Wind Tunnel Study. JAPCA 1985, 38, 135-143, doi:10.1080/08940630.1988.10466360.

2. ANSYS. Engineering Analysis System; Rev. 14.5; ANSYS, Inc.: Houston, PA, USA, 2014.

3. EPA. AP-42. Compilation of Air Pollutant Emission Factors; Quinta Edición; EPA: Washington, DC, USA, 1995.

(C) 2018 by the authors. Licensee MDPI, Basel, Switzerland. This article is an open access article distributed under the terms and conditions of the Creative Commons Attribution (CC BY) license (http://creativecommons.org/licenses/by/4.0/). 